\title{
Mobilització de classes, corporativisme i estat de benestar al Japó*
}

\author{
Lluís Valls Campà
}

\section{Resum}

En aquest article s'analitza i s'explica la conformació de l'actual sistema de relacions industrials al Japó utilitzant el marc teòric establert per Esping-Andersen per a l'explicació dels diferents tipus d'estat de benestar.

La utilització d'aquest model porta a considerar l'actual sistema de relacions industrials al Japó com el resultar de les eleccions racionals desenvolupades pels actors socials al llarg del periode historic des de la fi de la Segona Guerra Mundial, en lloc d'establir una explicació de tipus culturalista, que evitaria establir una vertadera explicació.

En primer lloc, es descriu el model de Esping-Andersen i es discuteix la situació del Japó en la seva classificació d'estats de benestar. En segon Iloc, s'apliquen el Japó les tres variables principals del model: la natura de la mobilització de classes, les estructures de coalició de la classe política i el llegat històric de la institucionalizzació del règim. Finalment, l'actual sistema de relacions industrials al Japó queda configurat con un sistema microcorporativista del benestar.

Paraules clau: estat de benestar, corporativisme, relacions industrials, Japó.

\section{Abstract. Mobility of class, corporatism and Welfare State in Japan}

The article examines the present Japanese industrial relations system, according to Esping-Andersen theoretical framework of analysis in order to undestand different forms of Welfare State.

Key words: Welfare State, corporatism, industrial relations, Japan.

\section{Sumari}

Introducció

El tègim d'estar de benestar al Japó

Natura de la mobilització de classes

Estructures de coalició de la classe política
Llegat històric de la institucionalització del règim

Conclusions

Bibliografia

* Basat en la comunicació presentada amb el mateix títol a la Conferència d'Estudis Japonesos a Catalunya de 1994, celebrada a Barcelona el 17 de juliol de 1994. 


\section{Introducció}

Quan es pretenen explicar les relacions laborals al Japo sovint apareixen dos temes clau: les relacions de tipus corporatiu i la provisió de benestar. D'aquesta manera, Dore (1989, p. 370) considera que el sistema de sindicats d'empresa $i$ les estructures de negociació interna d'aquestes, la seguretat i la provisió de serveis de benestar dintre de les empreses, l'estabilitat en l'ocupació, una ideologia de cooperació o corporativa, etc. permeten parlar d'un sistema de corporativisme del benestar a nivell d'empresa. Per la seva part, Lincoln i Kalleberg (1985, p. 740$)$ apliquen al Japó el concepte de corporativisme a nivell micro, el qual estaria caracteritzat per estructures organitzacionals i pràctiques de direcció que tenen per objectiu reforçar la lleialtat a l'empresa, l'obediència i la dependència dels seus treballadors (Shalev, 1990, p. 68).

En aquest treball adoptem aquestes aportacions com a punt de partida, i ens proposem argumentar per què es poden caracteritzar les relacions laborals al Japó posterior a la Segona Guerra Mundial com un sistema de microcorporativisme del benestar $i$ com sha anat conformant aquest sistema des d'aquell moment. Ens allunyarem d'explicacions de tipus culturalista, sense negar la influència d'elements culturals en la configuració de les relacions industrials a cada país, però ens centrarem a elaborar una explicació que es basi en les eleccions racionals desenvolupades al llarg del temps pels diferents actors socials!

Amb tal finalitat adoptem el marc teòric que estableix Esping-Andersen (1990) per a l'explicació dels règims d'estat de benestar. Un concepte fonamental que estableix aquest autor és el de desmercantilització del treball. La desmercantilització del treball consisteix en la instauració d'uns serveis de benestar que alliberin substancialment la persona de la seva dependència del mercat $\left(1990\right.$, p. 22) ${ }^{2}$. Els drets de desmercantilització, segons el mateix autor, s'han desenvolupat al llarg de la història de diferents formes i en diferent grau en els diferents Estats, la qual cosa ha donat lloc a tres règims, tipus ideals, d'estat de benestar: el règim liberal, el règim conservador $i$ el règim socialdemòcrata. En aquest mateix ordre, els tres règims mostren un grau de desmercantilització ascendent.

El règim liberal, que busca la incentivació del trebail, consisteix en un estat de benestar de tipus residual que només cobreix, després de comprovar l'estat de necessitat, els subjectes que han fracassat en el mercat; la resta de sectors socials cerquen la satisfacció del benestar en el mercat. Altres trets que caracteritzen aquest règim d'estat de benestar són l'absència de relacions de tipus

1. Del que es tracra és d'evitar les explicacions que consideren el japó com un cas únic, fruit de la seva propia cultura i incomprensible per qui no participa d'aquesta (que és una forma de no proporcionar una explicació). Així, realitzem una anàlisi que se centra en aspectes que permeten una comparació amb altres nacions i que proporcionen una explicactó racional.

2. A través d'aquest concepte Esping-Andersen centra el punt d'atenció de l'estudi de l'estat de benestar en el significat de la despesa social quant a la redefinició de les relacions socials que produeix, més que quant a la grandària de la despesa. 
corporatiu i l'absència de compromís de l'Estat per aconseguir la plena ocupació; és més, l'existència d'un "exèrcit de reserva de força de treball" en atur és considerada com un factor que afavorirà una contenció salarial, una baixa inflació, i el creixement de l'economia i la creació de llocs de treball.

El règim conservador es caracteritza perquè l'Estat proporciona uns serveis socials lligats al treball, ja sigui de forma corporativa (existència d'estatus de provisió de benestar diferenciats per diferents professions), i/o estatista (existència d'un estatus privilegiat diferenciat en la provisió de serveis de benestar als empleats públics). Aquest tègim tampoc no es compromet amb la plena ocupació, però sí en la prestació de subsidis als aturats —encara que de forma complementària als serveis que prestin la família i organitzacions de tipus caritatiu. El fet que es produeixin relacions corporatives que mantenen els privilegis dels treballadors ocupats porta al manteniment d'uns salaris elevats, un atur elevat, una inflació elevada i unes despeses socials elevades.

Finalment, el règim d'estat de benestar socialdemòcrata es caracteritza per la provisió universal de serveis socials com a drets de tot ciutadà. En aquest règim I'Estat es compromet amb la plena ocupació ${ }^{3}$, la qual és necessària per tal de fer possible la provisió d'un elevat nivell de prestacions socials universals, i també tenen lloc unes fluides relacions de tipus corporatiu, però que engloben el conjunt dels treballadors i les classes mitjanes, sense produir-se estatus diferenciats segons les categories professionals, sinø assegurant un estatus de provisió de benestar universal per a totes les classes.

Amb tot això veiem com, segons el model tedric dibuixat per EspingAndersen, amb cada règim d'estat de benestar van associades unes determinades formes de relacions laborals i com la major o menor dependència del treballador respecte del mercat, a causa de la major o menor desmercantilització del treball, afecta les relacions entre treball $i$ capital i la forma de fer front als problemes que es plantegen a la societat. El mateix Esping-Andersen diu:

Quan els treballadors depenen per complet del mercat, és dificil que es mobilitzin per a accions solidàries. Com que els seus recursos reflecteixen les destgualtats del mercat, apareixen les divisions entre els que són a dintre i els que són a fora; aixd fa dif́cil la formació de moviments obrers. La desmercantilització reforça l'obrer i debilita l'autoritat absoluta dels empresaris (Esping-Andersen, 1990, p. 22).

A causa d'aquesta interrelació entre el règim d'estat de benestar i les relacions laborals, considerem que el model teòric d'Esping-Andersen per a l'explicació de l'estat de benestar és també útil per a l'anàlisi de les relacions laborals.

3. L'ocupació és entesa com un dret de tot ciuradà en edat de treballar, i per tant es desenvolupen mecanismes per afavorir el treball femení i de grups amb dificultats per a la inserció laboral. Al mateix temps, la plena ocupació garanteix que el grup de subjectes que perceben prestacions socials públiques no sigui insostenible i que el grup de contribuents sigui elevat. 
Per aquesta raó considerarem quin és el règim d'estat de benestar que correspon al Japó segons la classificació d'aquest autor i quins pot tenir sobre les seves relacions laborals. Però Esping-Andersen també estableix que el tipus de règim d'estat de benestar que s'hi desenvolupa depèn de tres factors:

1. La natura de la mobilització de les classes, especialment de la classe obrera. Aquesta variable es refereix als interessos (ideològics o professionals, universals o d'una branca industrial, seculars o confessionals) que persegueixen els diferents grups socials i que els impulsen a l'acció col.lectiva.

2. Les estructures de coalició de la classe política. És a dir, les condicions que es donin a nivell parlamentari entre grups polítics representants de diferents grups socials, que generin polítiques que possibilitin el desenvolupament d'un tipus o un altre d'estat de benestar. Especialment, l'existència d'una coalició entre partits d'esquerra i de dreta que asseguri un consens sobre l'estat de benestar malgrat les alternances de partits en el govern, és considerada per Esping-Andersen un requisit per al desenvolupament d'un estat de benestar de tipus socialdemòcrata.

3.) El llegat històric de la institucionalització del règim. Aquest consisteix en la institucionalització de determinades formes de benestar que afavoreixen uns grups o uns altres, s'hereten de períodes anteriors, la qual cosa porta a la creació o no d'interessos comuns en la defensa i en el desenvolupament de l'estat de benestar.

Encara que per aquest autor la principal variable independent explicativa del desenvolupament d'un règim d'estat de benestar o un altre és la coalició de la classe política ${ }^{4}$, considerem que les altres variables, $i$ especialment la natura de la mobilització de classes, són fonamentals a l'hora d'explicar cl desenvolupament de les relacions laborals $i$, en el cas present, a l'hora d'explicar el desenvolupament del microcorporativisme del benestar al Japó. Aquesta postura és deguda a què aquests elements ens permetran explicar l'absència d'incentius per al desenvolupament d'un vertader corporativisme a nivell macro (nacional) i/o meso (branca industrial), i l'existència d'incentius per al desenvolupament d'un microcorporativisme del benestar.

D'aquesta manera queda justificada la utilització del model teòric que EspingAndersen estableix per a l'explicació dels diferents règims d'estat de benestar en la nostra explicació de les relacions laborals, la qual desenvoluparem, en primer lloc, analitzant la situació del Japó en la classificació dels règims d'estat de benestar establerta per aquest autor; en segon lloc, estudiarem la natura de la mobilització de classes al Japó i la seva relació amb el corporativisme; en tercer lloc, les estructures de coalició de la classe política, $i$, finalment, el llegat històric de la institucionalització del règim d'estat de benestar al Japó.

4. Esping-Andersen, 1990 , p. 29-33. El mateix autor basa el seu punt de vista teòric amb l'anàlisi estadistica de dades empiriques extreces d'una mostra de divuit països, entre els quals es troba el Japó, referents a variables sociopolitiqutes i socioecondmiques (vegi's el capítol V de la mateixa obra). 


\section{El règim d'estat de benestar al Japó}

La situació del Japó en la classificació de règims d'estat de benestar d'EspingAndersen no queda clara, ja que mostra trets del tipus de règim liberal i del tipus de règim conservador. De fet, aquest autor considera que el Japó mostra un grau mitjà d'atributs de règim conservador, un grau elevat de liberalisme i un grau baix de règim socialdemòcrata. Aquesta situació del Japó es deu a què la provisió privada de serveis socials representa un percentatge elevat sobre el total, hi ha un grat baix d'igualtat entre els beneficis socials percebuts pels diferents subjectes, els casos en què el servei social es presta només després de testar la situació de necessitat són nombrosos i també ho són els esquemes de pensions públiques diferenciats segons l'ocupació, a més, els plans de pensió públics per als funcionaris representen un elevat percentatge del PIB ${ }^{5}$ (Esping-Andersen, 1990, p. 69-86).

Amb tot això, Esping-Andersen considera que el Japó presenta un grau de desmercantilització mitjà-baix (1990, p. 52), tot i que aquí creiem que aquest grau de desmercantilització està sobrevalorat en el cas de les pensions - en el cas dels altres serveis socials (l'asseguranca de malaitia i atur) Esping-Andersen considera que al Japó es dóna una baixa desmercantilització-, ja que en la forma de mesurar aquest factor l'autor no té en compte la diferència qualitativa entre la provisió, d'una banda, de les pensions estatals i particulars, i, de l'altra banda, quan una part important de la pensió és provëda per l'empresa. En el primer cas la pensió no es veu afectada, en principi, per un canvi d'empresa, mentre que en el segon cas sí, per dues raons. En primer Iloc, un canvi d'empresa significa una reducció de la pensió, ja que el volum d'aquesta va lligat als anys d'antigutitat en l'empresa; $i$, en segon lloc, perquè de la salut econòmica de l'empresa depèn que aquesta pugui pagar les pensions als seus empleats quan es jubilin. Així, la provisió de les pensions per part de l'empresa es converteix en un mecanisme que incrementa la dependència de l'empleat respecte de l'empresa en la prestació de les pensions, i produeix uns incentius elevats per mantenir la seva fidelitat a l'empresa, amb la qual cosa s'incrementa el sentit de mercaderia del treball.

El fet que les empreses proporcionin una part important dels serveis socials, la qual cosa significa que s'estableixen diferents estatus entre els treballadors de diferents empreses, ens porta a considerar que el Japó mostraria un règim d'estat de benestar corporativista força conservador, però no a nivell de serveis de benestar públic, sinó a rivell privat d'empresa; mentre que a nivell públic el

5. Segons les dades utilitzades per Esping-Andersen, les pensions públiques representen el $54,4 \%$ de la despesa total en pensions, les pensions dels empleats públics representen el $22,8 \%$, les pensions ocupacionals l' $11,4 \%$ i les pensions particulars l' $11,4 \%$. Atxí, tespecte als altres països de la mostra, el Japó destaca per l'elevat percentatge de despesa en pensions privades i en pensions per a empleats públics (Esping-Andersen, 1990, p. 85).

6. A més, les dades referents a les pensions proveldes per l'empresa utilitzades per EspingAndersen en el cas del Japó són incompletes, tal com reconeix el mateix autor (vegi's EspingAndersen, 1990, p. 104). 
règim seria força liberal $\mathrm{i}$ amb trets de conservadurisme, especialment estatalista a causa de l'estatus diferenciat dels treballadors públics.

Pel que fa al tema de la plena ocupació, malgrat que reconeixem els baixos índexs d'atur al Japó, podem considerar que es dóna una diferència fonamental entre la "plena ocupación japonesa i la plena ocupació característica dels règirms d'estat de benestar socialdemòcrates, ja que en aquests darrers l'ocupació és concebuda com un dret de tot ciutadà i per tant l'Estat es compromet en la creació d'ocupació pública, s'han creat serveis socials que faciliten l'accés i el manteniment de la dona en el treball, i no s'incentiven les jubilacions avançades (a més, aquesta falta d'incentivació no és via baixes pensions o difícil accés a aquestes) (Esping-Andersen, 1990, p. 150-153). Contràriament, al Japó el treball femení és vist com un complement $i$, per tant, en la majoria de casos, es destinen les dones a llocs de trebali de qualificació baixa, temporals, a temps parcial, i amb menor retribució que els homes ${ }^{7}$. Les dones abandonen l'activitat laboral a partir del casament o del naixement del primer fill. Quant a la jubilació, aquesta s'ha establert durant molt temps en una edat baixa (menys de 60 anys) $\mathrm{i}$, a causa de les pressions sindicals, finalment s'ha augmentat fins a aquesta edat (en la qual es comencen a percebre les pensions públiques). Però, a més, en molts casos, els primers anys de jubilació poden significar també un pas del treballador al segment secundari del mercat laboral, i és transferit a una empresa subsidiària amb unes condicions de treball i salarials inferiors (Murakami, 1988 , p. 4-5). Aquests tres fets ens mostren com la "plena ocupación japonesa no té el mateix significat que la plena ocupació dels règims sociademòcrates, i s'aproxima més al règim d'estat de benestar de tipus conservador.

\section{Natura de la mobilització de classes}

A través del concepte de natura de la mobilització de classes analitzarem quins són els incentius de les diferents classes socials, especialment les classes treballadores, per adoptar unes relacions laborals que s'allunyen d'un vertader corporativisme $i$ es configuren com un microcorporativisme del benestar.

En aquest sentit destaquen dos fets al Japó: 1) La dificultat per assolir una acció col-lectiva unificada a nivell macro per part dels treballadors, i la gran confrontació que s'ha produit en aquest nivell entre les diferents opcions. 2) El protagonisme que han adquirit els sindicats d'empresa en lloc dels sindicats als altres nivells.

Així, començarem comentant aquests dos aspectes, continuarem analitzant el funcionament dels sindicats d'empresa i les relacions laborals a nivell micro, i acabarem configurant el sistema de relacions laborals al Japó com a microcorporativisme del benestar (utilitzant les característiques que $\mathrm{Ph}$. Schmitter (1974) atribueix al corporativisme).

7. El Japó és el pais de l'OCDE que mostra una disparitat més elevada entre sexes en els salaris; les dones ocupades perceben de mitjana només el $60 \%$ del salari de què̀ gaudeixen els homes (Naohito, 1993, p. 4). 
A nivell macro, l'actuació dels sindicats japonesos des de la fi de la Segona Guerra Mundial ha estat molt politirzada, amb una gran implicació de les diferents organitzacions sindicals amb els partits polítics, fet que ha portat a un gran nombre de confrontacions, i durant els primers anys a una forta repressió contra el sindicalisme comunista (el qual també mostrava una predisposició a l'enfrontament amb l'empresariat i l'Estat) (Garon, 1992, p. 361-368; Shalev, 1990, p. 70-71). Així, dels dos sindicats majoritaris existents fins al 1989, el Consell General de Sindicats del Japó (Sohyo) donava suport al Partit Socialista del Japó (PSJ), mentre que la Confederació Japonesa del Treball (Domei) ${ }^{8}$ donava suport al moderat Partit Socialista Democràtic del Japó (PSDJ) (aparegut com a escissió del PSJ l'any 1960). A més dels factors ideològics, un altre factor que distancià el Sohyo de la resta de sindicats és el fet que aquesta organització representava majoritàriament treballadors del sector públic, mentre que les altres organitzacions ho feien del sector privat; d'aquesta manera tenien interessos diferenciats a causa del diferent estatus en la percepció de serveis de benestar, de la dependència dels salaris dels treballadors públics dels pressupostos de l'Estat, i de les diferències d'actuació estratègica que poden comportar les restriccions a les quals estan sotmesos els treballadors públics ${ }^{9}$. Les altres organitzacions sindicals nacionals d'importància eren la Federació de Sindicats Independents del Japó (ChuritsuRoren) i la Federació Nacional d'Organitzacions Industrials (Shin-Sanbetsu), les quals donaven suport al centre polític (Inohara, 1991, p. 125-131).

Aquestes divisions politiques han dificultat el desenvolupament d'una estratègia col-Lectiva conjunta de la classe treballadora, la qual cosa va endarrerir el principi de la unificació sindical fins a l'any 1987, en què va aparèixer una organització sindical unificadora de la Domei amb els dos sindicats de centre, la Confederació Sindical del Sector Privat Japonès (Rengo), a la qual dos anys més tard es va agregar també el Sohyo (fet que va provocar l'escissió del seu sector més esquerrà). De totes maneres la capacitat d'acció de Rengo es veu limitada pels factors que es comenten a la resta d'aquest apartat.

Un altre element que determina una baixa mobilització de classe dels treballadors ${ }^{10}$ i ens en mostra la natura particularista és la baixa legitimació dels

8. Després de la Segona Guerra Mundial els sindicats nacionals principals eren la Sodomei (que donava suport al govern conservador) i el Sambetsu (molt lligat al Partit Comunista). A causa de la repressió contra el sindicalisme comunista i de la forta intervenció del Parcit Comunista en aquest sindicat, el 1950 es va fundar el Sohyo a través de la fusió de la Sodomei i les faccions escindides del Sanbersu. Però poszeriorment van tornar a apareixer diferències internes lligades a la ideologia. A consequiència d'això la Sodomei es va escindir del Sohyo i aquest sindicat quedà sota control dels sectors socialistes.

La Domei va aparèixer l'any 1964 com a fusió de la Sodomei i la Zenro Kaigi. Tant la Domei com la Zento Kaigi eren favorables a la colllaboració amb el capital en l'increment de la productivizat per zal d'incrementar els salaris, i per tant escaven enfrontats amb el Sohyo (Garon, 1992, p. 366).

9. Per exemple, no disposen del dret de vaga, encara que aquesta prohibició de vegades és trencada durant el Shunto (Bailon, 1983, p. 6).

10. De la qual n'és una mostra el descens del $55 \%$ as $28 \%$ en la taxa de sindicació entre els anys I 949 i 1987 (Hroshi, 1989, p. 34), i al 24,4\% el 1992 (JETRO, 1994, p. 129). 
sindicats nacionals (nivell macro) i sectorials (nivell meso) —l'afiliació als quals és bàsicament a través dels sindicats d'empresa-, que es denota amb una taxa del $40,3 \%$ d'associacions per branca industrial no afiliades a cap associació nacional l'any 1987 , i una taxa del $37,4 \%$ de treballadors sindicats que no estan afiliats a cap dels quatre grans sindicats nacionals de 1981 (Chalmers, 1991, p. 189) - després de la unificació sindical Rengo, la taxa de treballadors membres de sindicats que no estan afliats a aquesta és del 39,9\% (JETRO, 1994, p. 128). Aquesta baixa legitimitat de les organitzacions sindicals - tant a nivell macro com a nivell meso- porta a què aquestes quedin allunyades dels afers que afecten directament les empreses. Així, les organitzacions sindicals a nivell macro i meso són considerades com a outsiders pels treballadors i pels sindicats d'empresa, són considerades com a organitzacions que han d'exercir una reivindicació política, a nivell de partits polítics, deixant de banda els problemes que afecten les relacions laborals (en un sentit ampli) a cada empresa, els quals són percebuts com un problema intern de l'empresa "inohara, 1991, p. 134-135). Així, l'activitat dels sindicats a nivell macro i meso es limita pràcticament a la cerca d'un acord d'increment salarial amb les organitzacions empresarials durant l'ofensiva de primavera (Shunto) -el qual després serà negociat a nivell d'empresa pel sindicat d'empresa i per tant no és vinculant - i a la coordinació de les accions reivindicatives que es realizzen durant aquest periode; mentre que totes les reivindicacions polítiques de canvis socials $\mathrm{i}$ totes les demostracions de força desapareixen tan bon punt s'arriba a un acord salarial (Inohara, 1990, p. 142-145). Com diu Ben-Ari (Benari, 1990) totes les reivindicacions polítiques de canvis socials i les demostracions de força (manifestacions, proclames, pancartes, vagues) formen més aviat part d'un ritual que es realitza cada any que d'una vertadera reivindicació.

El darrer element que ens mostra la baixa funcionalitat de les associacions sindicals nacionals i la seva exclusió del sistema corporatiu, és la reduïa participació de les associacions en els comitès consultius establerts pels diferents ministeris del Govern; participació que quan es dóna és per tractar temes poc importants o matèries en les quals el Govern intervé menys - com és el cas de l'ocupació $\mathrm{i}$ el benestar que han estat deixats a nivell intern de les empreses-. Les associacions sindicals queden apartades de la participació en la formació de les polítiques macroeconòmiques (Shalev, 1990, p. 84-86).

Aquesta absència dels treballadors en les negociacions a nivell macro -corporativisme ${ }^{12}$ sense els treballadors com estableixen Pempel i Tsunekawa (1979) - , porten a què el pes de la definició de les relacions entre el treball : el capital es desenvolupi a nivell d'empresa, fet que ens porta a analitzar les

11. Lúnica excepció és el cas del Sindicat de Mariners, el qual negocia directament amb l'Associació d'Armadors les condicions de contractació i de treball per al conjune de treballadors, independentment de la companyia a què pertanyin (Inohara, 1991, p. 128).

12. El fet que es produeix una relació corporativa entre el govern i les organitzacions empresarials és àmpliament acceptar per la bibliografia sobre el tema. Per tant, podem utilitzar el terme corporativisme, encara que sigui amb exclusió dels treballadors. 
relacions laborals a nivell micro. A més, podríem dir que la falta d'identificació entre els problemes particulars del treball a les empreses i l'actuació dels sindicats a nivell meso i macro pot ser, en bona part, entesa si considerem les característiques del microcorporativisme del benestar que es desenvolupa a nivell de l'empresa japonesa, tal com fem tot seguit.

En primer lloc, els sindicats d'empresa estableixen unes relacions intenses, fluides i permanents amb la direcció, i atriben a una coincidència d'interessos que se centra en la prosperitat de l'empresa com a sistema, es minimitza l'existència d'interessos contraposats amb la direcció, i es produeix en els nivells superiors una fusió entre la direcció del sindicat i la direcció de l'empresa (sovint d'entre els dirigents sindicals sorgeixen els futurs dirigents de l'empresa) (Ballon, 1983, p. 21-26; Dore, 1989). Aquesta percepció d'interessos comuns entre direcció $\mathrm{i}$ treballadors produeix una baixa conflictivitat laboral. Així, per exemple, la mitjana antual de dies de treball perduts per conflictes laborals entre 1976 i 1980 al Japó va ser d'aproximadament un milió, mentre que a França va ser de tres milions, al Regne Unit deu milions i als Estats Units trenta milions (Ballon, 1983, p. 26).

En segon lloc, els treballadors de l'empresa són representats pel sindicat d'empresa de forma monopolista, encara que de vegades sorgeix un segon sindicat d'empresa oposat al primer, l'aparició del qual és deguda a què un sector dels treballadors considera que el primer sindicar s'allunya excessivament dels interessos de la direcció de l'empresa $i$, per tant, dels interessos generals de l'empresa (entesa com a comunitat podem dir) (Ballon, 1983, p. 17). Aquest monopoli de les relacions amb la direcció, per parr del sindicat d'empresa, també porta a l'exclusió d'intervencions externes per part d'associacions sindicals i de l'Estat. Així, únicament un $10 \%$ dels conflictes laborals prodütts entre 1980 i 1981 van ser sotmesos a una intervenció externa a l'empresa, normalment la Comissió de Relacions Laborals, per tal que exercís una conciliació informal; i rarament van tenir lloc els processos d'intervenció més formal com són la mediació i l'arbitració (Ballon, 1983, p. 27).

En tercer lloc, l'afiliació al sindicat d'empresa és obligatòria per als treballadors fixos (i prohibida per als treballadors temporals) en la majoria de casos, amb l'amenaça d'acomiadament si no es compleix. A més, el sindicat d'empresa té un important paper en la gestió dels serveis de l'empresa (per exemple, els serveis socials i de benestar) i en la implementació de les decisions adoptades, $i$ es constitueix en un mecanisme per aconseguir lobediència, ja que els dirigents sindicals posseeixen un gran poder sobre les jerarquies inferiors del sindicat i els treballadors perquè participen en la presa de decisions sobre contractació, ascensos, formacio, organtizació del treball, mesures disciplinàries, etc. (Inohara, 1991, p. 135; Balion, 1983, p. 16-21; Dore, 1989)

En quart lloc, el treballador depèn de la provisió dels serveis socials de l'empresa, a causa dels trets de règim liberal d'estat de benestar (quant a la provisió pública) que ha adoptat el Japó i perquè la quantia de la pensió depèn de la grandària de l'empresa i dels anys que s'hi ha treballat. Així i tot, la grandària de l'empresa és el factor principal que determina la quantia de la pensió que 
es cobrarà d'aquesta, frns i tot per sobre del nivell d'estudis dels empleats (el qual és tradicionalment considerat el diferencial bàsic en les classificacions salarials). D'aquesta manera, l'any $1987, \mathrm{i}$ amb una antiguitat de trenta anys a l'empresa, mentre a les empreses de 1.000 treballadors o més els licenciats universitaris percebien una mitjana de 20,2 milions de yens de pensió, els graduats de High School percebien 14.4 milions i eis graduats de Middle School 10,8 milions, en les empreses de menys de 1.000 empleats les pensions significaven una mitjana de 10,4 milions, 8,3 milions i 7,4 milions, per les mateixes categories d'estudis ${ }^{13}$ (Ballon, 1988, p. 32). Finalment, dintre l'empresa es produeix un mercat del treball radicalment dual entre treballadors fixos it treballadors temporals (normalment dones, joves estudiants i immigrants). Així, aquests segons estan exclosos del sindicat d'empresa i no disposen de representación ni dels salaris i els avantatges socials dels trebailados fixos (vegi's Shalev, 1990).

En aquest punt hem de considerar les característiques del model de corporativisme establert per Schmitter, en les quals, si substituïm el paper de l'Estat per la direcció de l'empresa $i$ les comparem amb els paràgrafs anteriors, veiem com podem dir que al Japó es desenvolupa un microcorporativisme del benestar. Aquestes caracterfstiques del corporativisme suposen l'existència de: 1) grups d'interès amb un monopoli representatiu; 2) que amb freqüència es relacionen jeràrquicament entre si; 3) que posseeixen la facultat d'aplicar sancions als seus membres; 4) que configuren activament els interessos que representen; 5) governen realment i explícitament els seus membres; 6) mantenen relacions intimes amb l'Estat, i 7) sovint comparteixen amb aquest la responsabilitat de la formulació i l'execució d'una determinada política (Schrnitter, 1974, p. 260-261) ${ }^{14}$. El de grups monopolístics en la representació dels interessos porta a què excloguin a d'altres grups i es produeixi un dualisme entre els que tenen accés a la presa de decisions $i$ els que en queden fora ${ }^{15}$ (Coates, 1989, p. 233; Williamson, 1989 , p. 223-224).

Aquest microcorporativisme del benestar, juntament amb el sistema d'ascensos i increments salarials per antiguitat, la dualització de les empreses, la forma de contractació, l'organització per grups funcionals (vegi's Hechter, 1987, p. 179-181)

13. Així, l'any 1987 , en les empreses de menys de 1.000 empleats un graduat de Middle School - després de trenta anys de servei a la mateixa empresa- percep un $88,8 \%$ de la pensió que percep un graduat de High School a la mareixa empresa, perd̀ només un 68,3\% de la pensió que percep un graduat de Middle School en una empresa de 1.000 empleats o més. Aixi mareix, un graduat de High School en una empresa de menys de 1.000 empleats percep un $79,7 \%$ de la pensió que percep un graduat universitari de la mateixa empresa, pero un $57,4 \%$ del que percep un graduat de High School en una empresa de 1.000 empleats o més. I un llicenciat universitari d'una empresa de menys de 1.000 empleats percep només el $51,4 \%$ de 12 pensió que percep un liticenciat universitari en una empresa de 1.000 emplears o més.

14. Citat a Coates $(1989$, p. 233$)$

15. Shalev (1990) considera que el factor fonamental per comprendre el tipus de relacions laborals japonès és aquest dualisme, el qual es produeix de forma molr clara en el mercat laboral japonès, tant entre empreses com intra empreses. Així, segons aquest autor, les relacions corporatives serien un aspecte secundari en el cas del Japo. 
i l'elevada mobilitar funcional i geogràfica ${ }^{16}$ produeix una gran dependència ${ }^{17}$ i submissió del treballador respecte de l'empresa, la qual cosa ens pot explicar que el treballador s'identifiqui amb la seva empresa en lloc de fer-ho amb la resta de treballadors i es desdibuixin les classes socials i es dificulti la mobilització de classe.

\section{Estructures de coalició de la classe política}

Seguint el model d'Esping-Andersen, passem a analitzar les estructures de coalició de la classe política, les quals consisteixen en les coalicions parlamentàries que es produeixen i possibiliten el desenvolupament d'un determinat règim d'estat de benestar. Aquest element ens interessa tant pel seu efecte en les relacions laborals de forma indirecta a través de l'estat de benestar, com pel seu efecte directe, ja que l'existència d'una coalició política o d'una altra afavorirà o no l'establiment d'unes determinades formes de relacions laborals que permetin una participació més gran dels treballadors.

Segons el mateix autor, les estructures de coalició de classes tenen com a base la formació de classes. Aquest fet determina que en els moments inicials de la industrializzació, quan encara hi havia una important proporció de població ocupada en l'agricultura, la consecució d'una coalició política entre els treballadors i els agricultors fos indispensable per iniciar el desenvolupament d'un estat de benestar tendent al règim sociaidemòcrata; aquesta possibilitat dependrà de la factible articulació d'interessos entre les classes treballadores i els agricultors (Esping-Andersen, 1990, p. 30-31). Aquesta mateixa situació es va produir al Japó de la postguerra però sense realitzar-se una coalició entre les classes treballadores i les classes rurals, com veurem seguidament. El Parlament (la Dieta) del Japó posterior a la Segona Guerra Mundial ha estat caracteritzat per l'hegemonia d'una coalició conservadora. Aquest fet ha impedit l'establiment de programes socials més desmercantilitzadors i de formes de participació corporativista amb participació dels treballadors a nivell macro i meso.

Aquest fet es podria explicar com a fruit de quatre factors, entre d'altres: En primer lloc, el pes de la població electoral agrària, la qual representava el $45,5 \%$ de la població ocupada l'any 1947 (Watanuki, 1991, p. 56) i a més ha estat sobrerepresentada a causa del gerrymandering en els districtes electorals (Eccleston, 1989, p. 128). Aquest electorat dóna suport al Partit Liberal Democràtic (PLD) a causa del seu sistema de faccions, amb les xarxes de líders locals i compensacions que estableix; també per la dependència dels agricultors de la burocràcia estatal, que ha de protegir i subvencionar les seves pro-

16. Al voltant del $30 \%$ dels treballadors japonesos d'entre els 40 i els 60 anys s'han de desplaçar per períodes llargs liuny del seu domicili i de la seva famítia per desenvolupar tasques encomanades per la seva empresa (Naohiro, 1993, p. 4).

17. Tots aquests aspectes estan ampliamet exposats en la bibliografia sobre les relacions laborals al Japó, però destaca per la seva profunditat la clàssica aportació de Dore (vegi's Dore, 1989). 
duccions (Pempel i Tsunekawa, 1979, p. 268-269; Eccleston, 1989, p. 130), i a causa de la no identificació d'aquesta població amb el Partit Comunista del Japó (PCJ) ni amb el Partit Socialista del Japó (PSJ), que són considerats representants dels "treballadors no propietaris urbans". N'és un factor explicatiu el fet que, amb la reforma agrària desenvolupada durant l'ocupació americana, el govern conservador va convertir els agricultors desposseïts en petits propietaris (Watanuki, 1991, p. 57).

El segon factor que cal considerar és la importància numèrica de treballadors autònoms, petits empresaris i comerciants, els quals se senten més identificats amb un Estat liberal, que desenvolupi una política impositiva baixa, que primi el creixement econòmic per sobre dels aspectes socials i que protegeixi les seves produccions respecte de l'exterior (Watanuki, 1991, p. 62; i Pempel i Tsunekawa, 1979, p. 268-269).

El tercer factor és, com mostra Watanuki, la pèrdua de pes del PSJ i del PSDJ a causa de la seva dependència financera del Sohyo i de la Domei respectivament, dependència que els ha portat a defensar els interessos dels treballadors que hi estan sindicats, i per tant que ja disposen d'uns importants serveis de benestar a nivell d'empresa. Aquest fet allunya el 70\% dels treballadors (els no sindicats) de la identificació amb aquests partits. A més, el PDSJ troba el seu electorat circumscrit a unes determinades zones geogràfiques, ja que la Domei té una implantació desigual geogràficament a causa de la distribució territorial de la indústria (Watanuki, 1991, p. 146).

Finalment, el quart factor és el desdibuixament de les classes que produeix. el dualisme del mercat laboral i el microcorporativisme del benestar que hem descrit, el qual es va veure impulsat per la precària situació de la postguerra, que va afavorir l'acceptació per part dels treballadors d'un sistema de benestar interior a l'empresa, la qual estava interessada a retenir la ma d'obra escassa i a la qual havia de proporcionar una elevada formació. A més, aquesta situació es va veure reforçada, com estableix Watanuki (I991, p. 63), per l'augment salarial a què va donar lloc el creixement econòmic durant els anys seixanta.

\section{Llegat històric de la institucionalització del règim}

Finalment, ens referim al tercer factor del model teòric d'Esping-Andersen, $\mathrm{cl}$ ilegat històric de la institucionalització del règim d'estat de benestar, que consisteix en les formes d'estat de benestar heretades de períodes històrics anteriors, les quals porten a què es donin o no uns interessos $i$ uns drets adquirits comuns entre diferents classes, fet que facilitaria la seva mobilització i la seva coalició a niveli polític.

En el cas del Japó, ja amb anterioritat al règim dictatorial previ a la Segona Guerra Mundial, s'inicia l'organització de sindicats d'empresa i certs serveis socials interns a aquesta (Dore, 1989, p. 456-458), en un context de règim d'estat de benestar de tipus liberal (a nivell econòmic més que polític) que limita l'assistència social als mínims indispensables. El període de dictadura fins a la rendició del Japó és un període on totes les activitats queden subor- 
dinades a la maquinària de guerra i es proudeix una forta repressió del moviment sindical i dels partits polftics (vegi's Garon, 1992).

Amb posterioritat a la Segona Guerra Mundial el sistema de sindicats d'empresa i serveis socials interns a aquesta s'assenta i no troba oposició a causa, a més de la precària situació de postguerra i de la dispersió d'interessos de les diferents classes, del fet que aquesta herència de falta de serveis socials públics porta a què els grups amb més poder econòmic busquin la provisió dels serveis socials al mercat, $i$ els altres grups la busquin en formes microcorporativistes a l'empresa i en la famflia. Aquest desenvolupament, juntament amb la repressió del sindicalisme comunista i la diferent natura de la mobilització de classes - com hem vist en els apartats anteriors- porta a la consolidació d'aquest sistema de relacions laborals i forma de microcorporativisme d'estat de benestar. En el període de gran creixement econòmic dels anys seixanta el sistema funciona sense problemes i s'acaba d'assentar, però a partir de la crisi dels anys setanta es mostra com el sistema de microcorportisme del benestar impedeix una coalició de classes i reparteix els costos i els beneficis de la producció de forma diferencial entre els diferents grups socials - i entre els diferents grups de treballadors-, la qual cosa incrementa les diferències entre els diversos segments del mercat laboral i dificulta encara més la possibilitat d'una mobilització i una coalició de classes que permetria una evolució de l'estat de benestar i de les relacions laborals.

\section{Conclusions}

A través dels diferents apartats que hem desenvolupat hem vist com es poden proporcionar arguments per comprendre les relacions laborals al Japó sense caure en postures que les atribueixen a una cultura japonesa única. A través de l'estreta relació entre règim d'estat de benestar i forma de relacions laborals, i utilitzant el marc teóric establert per Esping-Andersen, hem proporcionat arguments en favor de la caracterització del sistema de relacions laborals japonès com a microcorporativisme del benestar. Així, a través de l'anàlisi que hem realitzat de la natura de la mobilització de classes, les estructures de coalició de la classe política i el llegat històric de la institucionalització del règim d'estat de benestar, podem dir que el sistema de relacions laborals japonès i el règim d'estat de benestar que s'han desenvolupat en aquest pais amb posterioritat a la Segona Guerra Mundial són fruit d'unes determinades estratègies de dominació i d'unes circumstàncies objectives a les quals calia fer front, juntament amb la divisió política de les classes treballadores, la impossibilitat de desenvolupar un projecte de caire socialdemocrata a nivell parlamentari i 'herència del règim d'estat de benestar liberal i amb tendèncias corporativistes anterior a la Segona Guerra Mundial.

Aquest microcorporativisme del benestar, caracteritzat per unes relacions corporatives intenses a nivell d'empresa, una exclusió dels treballadors de les relacions macrocorporatives, una dependencia respecte de l'empresa en les prestacions socials, $i$ un marcat dualisme del mercat de treball, incideix al mateix 
temps en els interessos dels diferents grups socials i en la natura de la mobilització de classes, la qual cosa produeix una perpetuació del sistema ${ }^{18}$. El punt de vista teòric que hem utilitzat pot ser acusat de mantenir certa circularitat en la causalitat. De fet, aquesta circularitat és manifesta en el model d'EspingAndersen:

Els drets socials, la seguretat dels ingressos, la igualtat i l'eradicació de la pobresa que un estat de benestar universalista persegueix, són les precondicions necessàries per la força i la unitat que demanda el poder col-lectiu de la mobilització (EspingAndersen, 1990, p. 16).

O sigui que el règim d'estat de benestat modifica les condicions de classe, els seus interessos i la possibilitat de la formació de coalicions de classe, elements dels quals depèn el règim d'estat de benestar. Aquesta circularitat, perd, ajuda a comprendre les relacions laborals, tot reconeixent que és només una aproximació a una realitat més àmplia i complexa.

\section{Bibliografia}

BALION, R.J. (1983). Industrial Relations in Japan. Tokyo: Sophia University.

BALLON, R.J. (1988). Japan's Salary System. Tokyo: Sophia University.

BEN-ARI, E. (1990). "Ritual strikes, ceremonial slowdowns: Some thoughts on the management of conflict in large Japanese enterprisesm a: EISENSTADT, S.N. BENARI, E. Japanese models of conflict resolution. Tokyo: Yoshio Sugimoto.

CHALMERS, N.J. (1991). Industrial Relations in Japan. Nova York: Routledge.

DORE, R. (1986). Flexible Rigidities. Londres: The Athlone Press.

DORE, R. (1989). Fábrica británica, fábrica Japonesa. Madrid: Ministerio de Trabajo y Seguridad Social. (Edició original en anglès, 1973.)

Eccleston, B. (1989). State and Society in Post-War Japan. Cambridge: Polity Pess.

ESPING-ANDERSEN, G. (1990). The three worlds of welfare capitalism. Cambridge: Polity Press.

FUKUTAKE, T. (1989). The Japanese Social Structure. Tokyo: University of Tokyo Press.

GARON, S. (1992). El Estado y los Trabajadores en el Japon Contemporáneo. Madrid: Ministerio de Trabajo y Seguridad Social.

HECHTER, M. (1987). Principles of group solidarity. University of California Press.

HiRoshI, M. (1989), "Cambios en el movimiento sindical y en la conciencia de los trabajadores». Cuadernos de Japón, vol. I, núm. 2, p. 34-35.

INOHARA, H. (1991). Ressources humaines dans les entreprises Japonaises. París: Eyrolles. JETRO (1994). Nippon 1994. Tokyo: JETRO.

LINCOIN, J.R.; KALLEBERG, A. (1985), "Work organization and workforce commitment: a study of plants and employees in the US and Japanm. American Sociological Review, núm. 50, p. 738-760.

Minoru, M. (1989), "La fusión sindical hace tambalear a la oposición". Cuadernos de Japón, vol. I, núm. 2, p. 42-46.

18. Un secror que podria escapar d'aquest model de microcorporativisme del benestar i establir una certa correcció del sistema és el cooperativisme urbà (vegi's Silvà, 1993). 
MURAKAMI, K. (1988). Retirement Benefits and Pension Plans in Japan. Tokyo: Sophia University.

NAOHIRO, Y. (1993). Economic interpretation of the Japanese employment system. Tokyo: Foreign Press Center.

PEMPEI, T.J.; STUNEKAWA, K. (1979), "Corporatism without labor? The Japanese anomalyn a: SCHMITTER, P.C.; LEHMBRAND, G. Trends towards corporatism intermediation.

SHALEV, M. (1990). "Class conflict, corporatism and comparison: A Japanese enigman a: EISENSTADT, S.N. Japanese models \& of conflict resolution. Tokyo: Yoshio Sugimoto.

SHIMADA (1989). "Estábamos tan unidos". Cuadernos de Japón, Vol. I, núm. 2, p. 47. 49.

SHMITTER, P.C. (1974). "Still the century of corporatism?". The Review of Politics, 36(1), p. 85-131.

Silva, A. ( 1993 ). Kyodo Kumiai. Barcelona: Institut per a la Promoció i la Formació Cooperatives. Departament de Treball. Generalitat de Catalunya.

WaTANuKi, J. (1991). "Social Structure and Voting Behavior" a: Flavacan; KOHEi; MiYAKE; RiChaROSON; WaTANUKI. The Japanese Voter. Yale: Yale University Press.

WILLIAMSON, P.J. (1989). Corparatism in perspective. An introductory guide to corporatist theory. Londres: Sage Publications. 